\title{
THE ANATOMY OF A DISTANCE EDUCATION COURSE: A CASE STUDY ANALYSIS
}

\author{
Kay E. Vandergrift \\ School of Communication, Information and Library Studies \\ Rutgers University, the State University of New Jersey \\ kvander@scils.rutgers.edu
}

\begin{abstract}
This case study of a distance education course in children's literature focuses on the creation of an interpretive community and the importance of that community in online learning. It also refines Michael G. Moore's work on transactional distance to include the concept of a faculty member's "restrained presence" in an effort to facilitate students' personal responsibility for their own learning and for community building in an online learning environment.
\end{abstract}

\section{KEY WORDS}

Learning effectiveness, Interaction, Electronic trail, Reader response theory, Interpretive learning communities, Restrained presence, Children's literature

\section{INTRODUCTION}

A graduate course- the human interaction and shared engagement with ideas and information- is a living entity. While there is a predetermined structure embodied in the course description and syllabus, the actual fleshing out of that skeletal structure takes place as active, constructivist learners engage with each other and with content to create both personal and social meanings. Thus, each time a course is offered, the course has its own characteristics and its own identity. Even if the infrastructure remains basically the same, the people, the environment, and the situations that bring the structure to life come together in new configurations as they find, shape, and create new meanings. Such is the richness of educational possibilities. The anatomy of the course presented here is just one of many possibilities for using the internet in distance education. It is not intended to be prescriptive. Rather it is shared as one of many possibilities in an ongoing discussion of distance courses for professional education.

\section{A. Theoretical Frame}

This research began with the intent to study the relationship between course design and dialogue in one distance education course in order to test Michael G. Moore's theory of transactional distance [1]. Moore's theory of transactional distance, first articulated in a 1972 article and named in 1980, is one of the key works in current discussions about distance education. His understanding of distance, not as physical space or geography, but as the space of potential misunderstandings between the intent of the teacher and those of learners, is essential to any study of distance education. According to Moore, transactional distance has two components, structure or course design and dialogue. Course design refers to the way educational objectives, teaching strategies, expectations for the behaviors and activities of learners, and evaluation procedures are communicated. Dialogue, according to Moore, is the interaction between teacher and learner for instructional purposes. Learner autonomy or the degree of self-direction 
exercised by the student is thus an important component of transactional distance.

Examining the exchanges among the nineteen students in this class, independent of faculty participation, however, led to an expansion of Moore's theory to include another form of dialogue. What this researcher calls "community dialogue," the engagement of an interpretive community in the process of shared meaning making, was the dominant form of communication and interaction in this virtual classroom. Another refinement of Moore's theory made here is the distinction between the course infrastructure and structure. This researcher's infrastructure includes everything in Moore's definition of structure plus a large body of additional content and contextual information designed for use by individual students exploring their own learning paths.

The case study analysis of this course is informed by the work of Moore, John Dewey [2], Louise Rosenblatt [3], and Stanley Fish [4]. Both Rosenblatt and Moore cite Dewey for the theoretical underpinnings of their work on, respectively, the transactional theory of literary response and the theory of transactional distance. Essentially, Dewey was concerned with experience as an interaction between person and environment, with the various conditions that interact with personal interests, and with needs to create interactive experience. Rosenblatt's transactional theory of literary response acknowledges the meanings a reader brings to a text and those a reader takes from the text. Thus, each reader's personal "story" in reading is the result of both textual content and personal and social context. Rosenblatt's work also comes into play because, at the same time a class is creating a learning community, it is creating personal and group meanings in response to literary works.

Fish's work on interpretive communities is most useful in describing the group process in this class. As students came to know each other, individually and as members of the group, they develop a very strong community with a shared history and shared meanings and understandings of literary works. These shared meanings carry over to new works and subsequent discussions and facilitate increasingly in-depth exchanges. The sense of trust that supports this kind of sharing may be more easily achieved in the online community because every student becomes known to the others in a way possible before now only in small seminar settings in physical classrooms. Thus, a complex relationship of "visibility" and "invisibility" probably allowed students to reveal more of themselves in very intense literary discussions.

For this case study the infrastructure of the course will be presented; then various methodologies will be described; and results of analysis will be reported.

\section{B. From Campus-Based to Online Course}

The Gender and Culture in Children's Picture Books course, the focus of the research described in this paper, provided an opportunity to reflect upon the differences between two versions of essentially the same course, one in the classroom and the other totally asynchronous. The course had been offered previously as an intensive, web-enhanced three-week summer class that met for approximately three hours each day. Students in the campus-based course typically spent another hour or two on campus, often working with a partner or in small groups, to share resources and to work on projects or assignments. They were also expected to explore and respond to a number of online enhancements attached to the course. The primary concern in the decision to convert this course to distance education was how to maintain the sense of camaraderie that was the natural result of intense daily interaction and involvement.

Prior to actually teaching this course online, a major distinction between a campus-based, web-enhanced 
course and an asynchronous online course was assumed to be that the faculty member would have to be much more involved in the dialogue in the asynchronous course. If the online interaction essentially is the course, it seemed reasonable that the teaching role would be exercised most fully through interaction. On the other hand, although the campus-based, web-enhanced course would require monitoring, it should require less faculty involvement because the online discussion is just one component of class interaction. In fact, the opposite was true. Campus-based students perceived the online dialogue as "extra" work, sometimes resented it, and needed constant encouragement to participate. Online students challenged, supported, encouraged, and expanded each other's perceptions, taking charge of the discussion and making the class their own.

The most striking change when this course moved from a physical to a virtual space was the increased amount of time required of both students and faculty. Pre-course structuring was much more precise and detailed than for the campus-based class, although efforts were made to make parts of the online structure nearly invisible to students. Online students need to be aware of the overall structure of the course, yet not feel that everything is predetermined. They must be able to find space for their own inquiries and needs within the assurance of a well-planned, content-rich and flexible learning environment with adequate navigational tools and support systems. This kind of planning is more demanding and more timeconsuming than the planning for the traditional classroom. The necessity for constant monitoring the online class was not fully recognized or prepared for in the pre-course planning.

\section{THE INFRASTRUCTURE OF THE ONLINE COURSE}

\section{Gender and Culture in Children's Picture Books}

[http://www.scils.rutgers.edu/special/kay/594syllabus.html] was divided into thirteen content modules, each of which had a number of resources attached. 
Figure 1: Infrastructure for the Course

\section{INFRASTRUCTURE FOR THE COURSE}

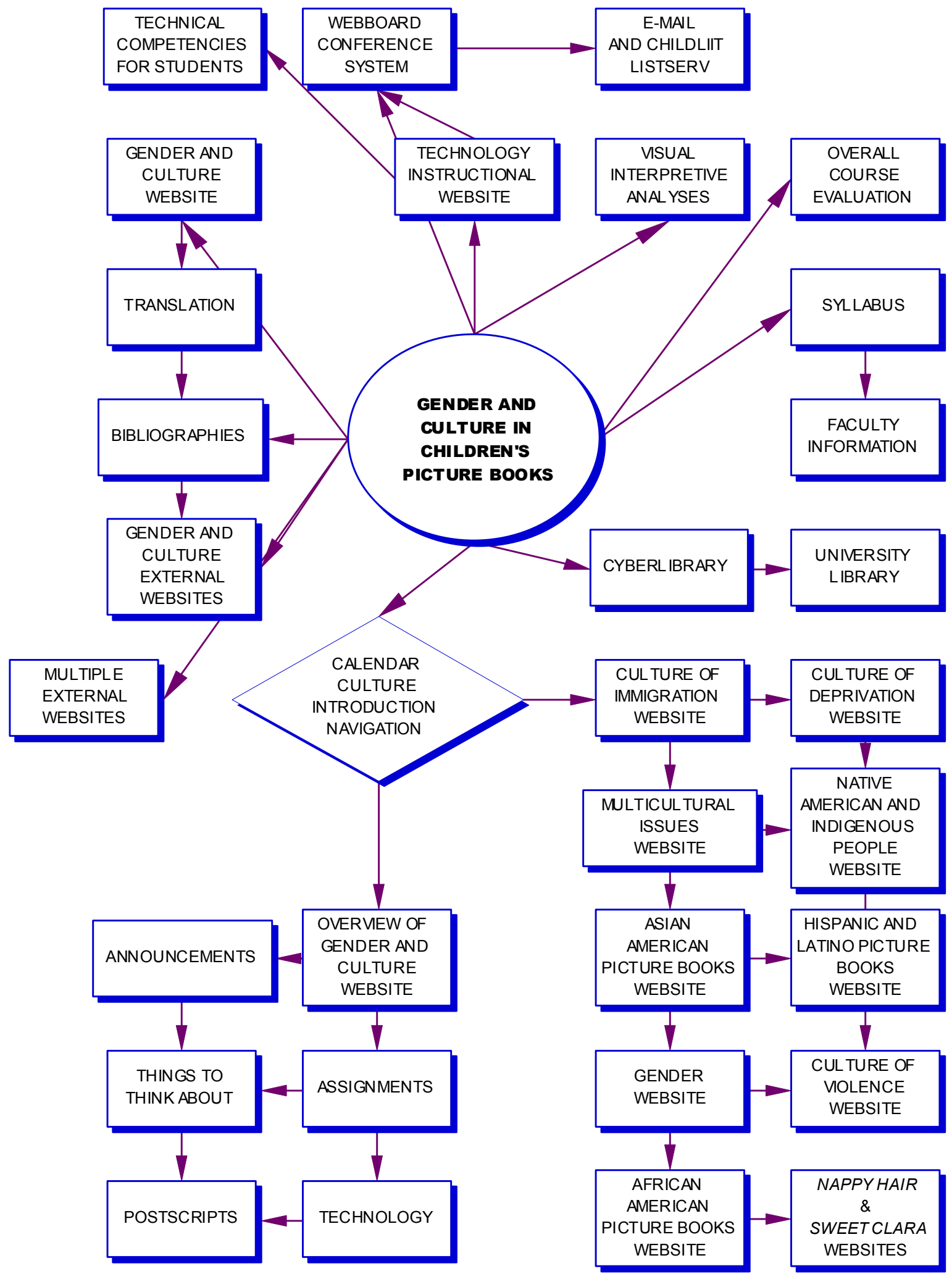


Most of these resources were hot links to faculty-created probe questions, bibliographies, and commentaries or to external sites with background information on the particular module, authors, illustrators, or books. Each of the modules was also an electronic conference using O'Reilly's WebBoard for threaded discussions. Additional discussion boards enabled students to post queries about "Assignments" or "Technology," to add a "Postscript" to a previously closed module, to make "Announcements," or just to suggest "Things to Think About." Figure 2 shows the number of postings in each of the modules for the course, representing an average of approximately 120 postings per student to the general discussions. Considering that many of these posts were long, complex analyses of aesthetic works, this is an impressive number.

Figure 2: Conference Modules and Posted Messages

\begin{tabular}{|c|l|}
\hline $\begin{array}{c}\text { NUMBER } \\
\text { OF POSTS }\end{array}$ & \\
\hline 83 & A Culture of Deprivation: The Poor, the Dispossessed \\
\hline 193 & African \& African-American Picture Books \\
\hline 114 & Asian-American Picture Books \\
\hline 172 & Gender \\
\hline 42 & Gender and Culture in Picture Books \\
\hline 195 & Hispanic and Latino Picture Books \\
\hline 140 & Immigration \\
\hline 54 & Multiculturalism \\
\hline 59 & Multiculturalism, Part 2 \\
\hline 68 & Nappy Hair Discussion \\
\hline 229 & Native American and Indigenous People \\
\hline 62 & Sweet Clara and the Freedom Quilt \\
\hline 166 & Violence \\
\hline 79 & Announcements \\
\hline 71 & Assignments \\
\hline 37 & Postscripts \\
\hline 234 & Technology \\
\hline 147 & Things to Think About! \\
\hline $\mathbf{2 1 4 5}$ TOTAL & $\mathbf{n = 1 8}$ \\
\hline
\end{tabular}

In total, there were sixty-one web pages developed for this course. Given the aesthetic content of this course, particularly the visual aspects of children's picture books, every effort was made to create visually interesting and attractive sites to create a balance of intellectual and aesthetic content. Only two portions of the overall web structure were password protected. The cyberlibrary contained over fifty articles and book chapters as PDF files, and it was a closed file for copyright protection. The other protected area was the conference board itself.

\section{A. Technological Aspects of the Course}

A somewhat unique aspect of this course structure as one of the first offerings in a new Youth Literature and Technology Advanced Certificate Program was the integration of instruction in various uses of technology. Although most students' previous compositions on the computer had been limited to word processing and email, they were required to create website assignments for this course. Thus, in the midst 
of continuing online literary discussion, they were given instructions on simple technological skills such as using html coding for italics, boldface, and color and for inserting hotlinks and images in a text message. After the expected explosion of different sizes, fonts, and colors in messages, use settled down to a less dazzling discussion board. One result that persisted, however, was students' inclusion of hotlinks to information that supported or expanded discussion topics. Online instructions for scanning and sizing images, use of an editor, and instructions for uploading to the internet proved far more difficult, both for students and faculty and resulted in the greatest proportion of student-teacher instructional dialogue, as defined by Moore, on the technology discussion board.

Despite technological difficulties, students were able to design and place their projects online. One required assignment was the design of a Visual Interpretive Analysis. (See http://www.scils.rutgers.edu/special/kay/analyses.html for examples of these projects.) This assignment was based on assumptions: 1. that each illustration in a picture book both communicates on its own and as one of a series of illustrations in the total aesthetic composition, and 2. that we can educate ourselves to see and interpret pictures more astutely by studying individual images and considering alternative interpretations of those images [5]. A second assignment offered options, and students created websites such as the following: Online Poetry Journey (see: http://www.scils.rutgers.edu/ carolhv/poetry.html). What becomes clear in studying these and other examples from the class is the intention to produce something of value to professionals in schools and libraries while including cultural issues and concerns that arose throughout the course.

\section{B. Collaboration}

Other unique features of this course were collaboration with another university, participation of invited guests, and interaction with ChildLit, a listserv for the scholarly discussion of children's literature. Professor Eliza Dresang of Florida State University was teaching a class that, while not parallel to this course, had some overlapping content. Therefore, the two faculty members planned for joint discussions on the Rutgers WebBoard at several times during the semester and even for the possibility of students from the two institutions working together on web assignments. Florida State University students were, with a few exceptions, actually attending weekly classroom sessions, and they were not as enthusiastic about this arrangement as were the Rutgers asynchronous distance education students. Only three students who were admitted to the FSU class as special distance education students participated with any regularity in the electronic dialogue. At Dresang's urging, other FSU students did share their impressions of a conference on Hispanic Children's Literature held in Florida during the semester. They also participated to some degree in the module on Native American literature because it included a guest originally invited by Dresang. The reluctance on the part of FSU students to take advantage of the opportunity to engage in dialogue about course content with students in another institution does not reflect on the quality of the students. It does, however, confirm what Rutgers students had already communicated quite clearly: online discussion is perceived as extra work, almost another course on top of the classroom interaction, for those in a campus-based course.

\section{Participation of Invited Guests}

One of several invited guests was included in the pre-active stage of teaching; others joined the group more spontaneously. Deborah Hopkinson, author of Sweet Clara and the Freedom Quilt was informed at the time the class was discussing her book and invited to participate. Marybeth Lorbiecki, author of Just One Flick of the Finger, found the class when searching online for her book, contacted the faculty member, and subsequently entered into the dialogue with students about her work. Debbie Reese, of the Nambé tribe and a doctoral student at the University of Illinois studying representations of Native Americans in children's literature, had previously agreed to join the class on that topic. Reese, both 
faculty members, and a few of the students are active participants on ChildLit; and a major controversy about a book's representation of Native Americans on that listserv coincided with the corresponding module in the class [6]. This timely, real-life professional concern led to one of the liveliest, most thoughtful and informative educational exchanges possible. Reese's presence and that of a Native American student from Rutgers on WebBoard throughout the controversy provided Native American perspectives and many insights that considerably expanded the learning community's understanding. The interaction with Childlit also helped to integrate students into the scholarly and research communities of the discipline.

\section{Discussion and Dialogue}

One of the issues often raised by faculty and administrators about distance education concerns the nature of conference board discussions, particularly the quality and depth of understanding demonstrated in such exchanges. Both students and faculty noticed the superior quality of the messages, especially the specificity and attention to detail in analysis of the books discussed and in response to the posts of classmates.

The semester began with a colorful, open-ended, metaphoric image posted on WebBoard. This was intended as a "warming-up" exercise, giving students participating in their first online class an opportunity to engage in a dialogue without the pressure of getting the right answer or performing for a grade.

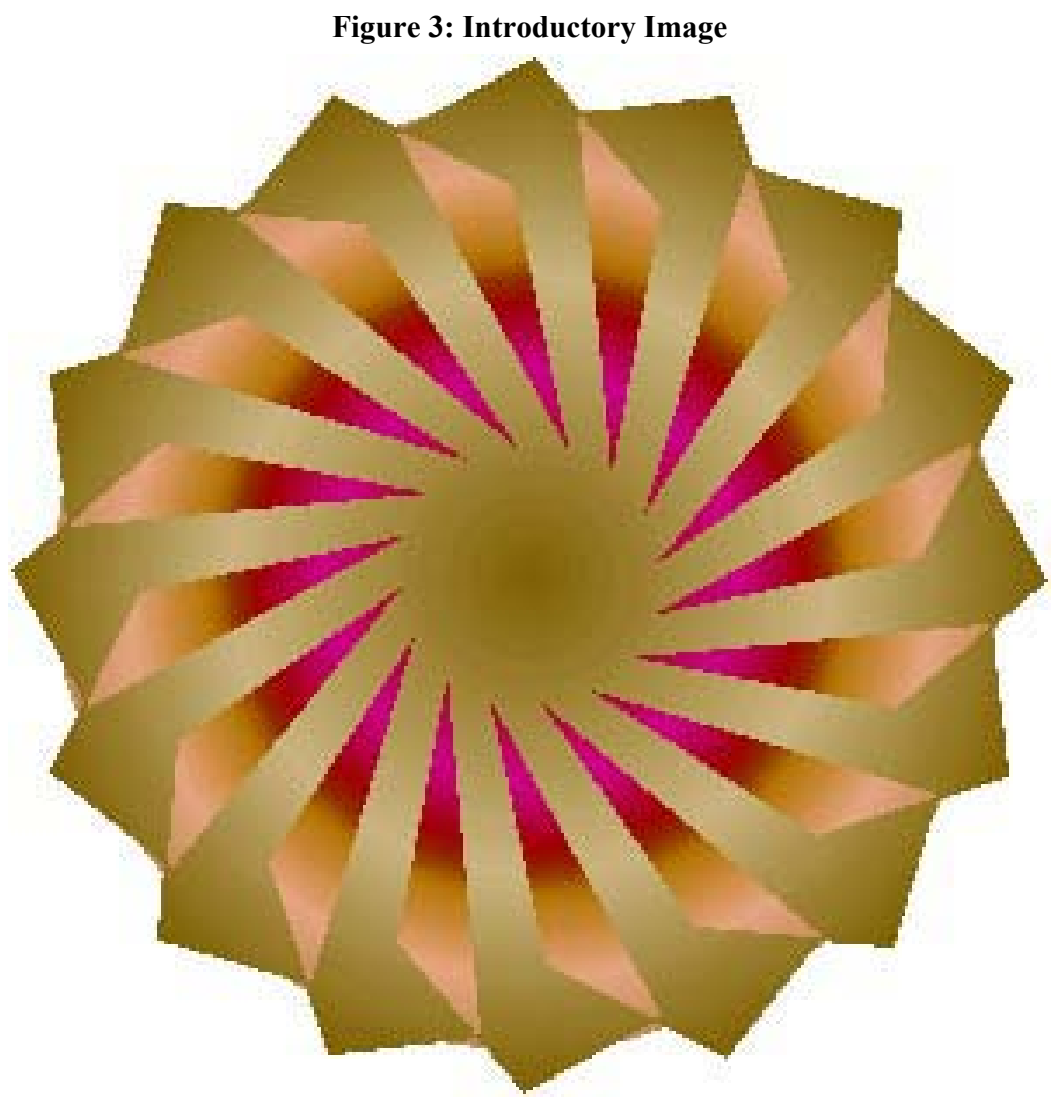

No specifications for response were given beyond the question "What meaning do you make of this?" The meanings elicited were far-ranging but did reflect the recognition of this exercise in a Gender and 
Culture course. The responses set both the tone and level of dialogue to follow. Two such examples are provided below:

I think this is a wonderful symbol for unity of cultures. I see the center as the nucleus, the divine higher authority, or the core genetic makeup that we ALL have in common. Then we branch out into our different groups, however you define yourself, wherever you feel you fit in. But we are still all connected to our core. Underlying all of that is this soup we call society, struggling to become a perfect circle, striving for unity in a graceful way. The gold is a powerful color, strong yet able to reach a melting point. The rose color has hope, uncertain yet nurturing. $\sim$ Jill

I sat and stared for quite awhile trying to get my thoughts in order and my eyes began to glaze in much the same way as looking at one of the magic pictures that have been in vogue for the last few years. When viewed in that way the figure becomes almost three dimensional with the center seeming to lead deep within the picture. The petals seem to almost pulsate, giving an impression of life and movement. Perhaps the figure should become a symbol for the class as we struggle to look deep into the heart of the concept of culture and to take what we have learned and let it flower into new ideas. If we also view the symbol as a pinwheel, perhaps we can extend the analogy into spinning off in new directions of thought and action as we take what we learn and apply it to our jobs and the children we work with. Janet

One might compare classroom-bound discussion to email exchanges that are ordinarily more spontaneous and ephemeral. In an online class, the discussion board is the class and, unlike spoken comments, written posts remain on the discussion board as basic building blocks of that learning community. In any discussion, one response triggers and challenges another; but, in the virtual learning community, a participant can take the time to think through, craft, and polish a response before posting it. Such responses are sometimes composed off-line and may even be held for a time of reflection before posting. Some students reported that most of their "class time" was spent in the evening hours, but that messages that were particularly important to them or those that they wanted to be certain were clear to others were held until after a fresh reading the next day before posting. Thus, on most topics there was some balance between immediate, spontaneous responses and more deliberate, often delayed, responses. It is also true that during the "delay," there may have been private, behind-the-scenes email exchanges between individuals in the learning community. The ability to reflect upon or to test out ideas and understandings with trusted peers undoubtedly improved the quality and the depth of the dialogues.

One thing that becomes evident quite quickly in an electronic learning community is the importance of writing skills. The computer screen is public in a way that student papers never are. Students who write clearly and convincingly make their voices "heard," influence others, and shape the content of the course much more powerfully than in the traditional classroom where the teacher's presence is seen and felt in a very different manner.

\section{E. Teacher As "Restrained Presence"}

Teaching online changes the role of faculty in several ways. Teacher as guide, facilitator, mentor, and manager for active, self-directed learners demands more restraint than faculty members ordinarily exercise in the classroom. It was difficult for this teacher not to respond immediately to a truly brilliant insight or, on the contrary, to confusion, muddled thinking, or misinformation. Immediate responses, however, inhibit replies from other students and encourage them to turn only to the teacher, rather than to each other, for feedback and intellectual leadership. A faculty role that balances restraint and presence seems to encourage students to make the online class their own. Of course, this takes place within the 
overall structure, situations, and problems designed by the teacher.

The intentional decision to exercise restraint in community dialogue increased the difficulty of feeling "in control" of the class and thus caused faculty discomfort at times. Deciding at what point it is important to add information or to prod students for further elucidation or for clearer articulation becomes increasingly difficult as the volume and the level of dialogue escalates.

Students also needed a period of adjustment to this restrained presence on the part of the teacher. As the teacher's initial intense involvement in discussions gradually diminished to encourage students to assume greater responsibility for their own learning, some participants seemed uncertain and asked for faculty assurance that they were progressing adequately or successfully. Often these were private messages, but at times, the general discussion included pleas for faculty direction. Although there was an attempt to restrain from too much faculty control, there was consistent, non-directive confirmation with comments such as "I'm really impressed with the breath and the depth of this discussion and with the group's ability to consider and assimilate a wide range of opinions"[7].

\section{F. Monitoring Discussions}

Part of the problem is the need to track the process of individual students while monitoring a lively, multifaceted, ongoing discussion. Faculty monitoring included being online several times a day throughout the semester and regularly checking the record keeping function of the discussion board that recorded the number of logins and the postings for each individual. Nonetheless, the need to keep a paper log for each student's participation became evident. A data record of the nature and extent of each student's participation was characterized using a set of codes and symbols developed to simplify record keeping. It took more than an hour each day to make meaningful notations as student postings were read, but this record was invaluable in monitoring student progress.

Figure 4: Electronic Trail

\section{STUDENT ELECTRONIC TRAIL}

STUDENT:

Date

Specific

Simple
Response

References $\begin{aligned} & \text { Text } \\ & \text { Discussed }\end{aligned}$

Illustration

Questions
Asked

Use of

Technology

Notes on the Posting

In the third week of this fifteen-week class, personal messages were sent to each student, assessing participation and progress toward class goals. This message included the number of logins and postings, as well as a summary of the analysis from Figure 4.

In this way, those who were "lurking" more than participating or those posting mostly simple responses 
such as "I agree" or "Thank you for the information," were easily identified. It was also important to identify students who ignored the illustrations in their discussions of picture books or those who seldom backed up personal opinions with any sort of evidence. This early diagnosis of responses helped to clarify expectations and improve the quality of intellectual involvement.

Although there was less public faculty participation than in a classroom, personal responses to individuals continued throughout the semester. The more options and the greater the number of resources available to learners, the greater was the need for a teacher to help at least some students sift through, sort out, evaluate, select, and use those resources in the process of making personal sense of an expanding, increasingly complex intellectual environment. Many of these private exchanges between a student and the teacher were, in essence, "office hours" or typical student-teacher conferences discussing individual assignments. A large number, however, were initiated by students who needed personal assurance that their online contributions were as valid and as important as those from classmates who had considerably more professional experience or were more comfortable with the technology.

Using the discussion board in the Gender and Culture in Children's Picture Books course as the database, a specific form of content analysis research [8] yielded findings that support the claim of consistent excellence in interaction. Using the module on Gender, an analysis of the grouped data of student responses was performed for three specific issues identified in Figure 5. Examples of comments coded for each of the categories appear in Figure 6.

Figure 5: Selected Student Response Categories

\begin{tabular}{|c|l|}
\hline $\begin{array}{c}\text { CATEGORY } \\
\text { CODE }\end{array}$ & \multicolumn{1}{c|}{ CATEGORY CONCEPT } \\
\hline 1 & Students Identify a Feminist Standpoint in the Books Read \\
\hline 2 & Students Use Illustrations to Validate Feminist Concepts \\
\hline 3 & Students Use Textual Analysis to Validate Feminist Concepts \\
\hline
\end{tabular}

Figure 6: Selected Student Responses by Categories

\begin{tabular}{|c|c|}
\hline CATEGORY & STUDENT COMMENTS \\
\hline 1 & "girls either equally sharing status in the community, or assuming leadership" \\
\hline 1 & $\begin{array}{l}\text { "Women are not afraid to stand outside of popular opinion in order to fight for } \\
\text { their rights" }\end{array}$ \\
\hline 1 & "two feminist women determined to orchestrate changes in a man's world" \\
\hline 2 & $\begin{array}{l}\text { "bobbins look so attractive, belying the dismal and dingy conditions (airless- the } \\
\text { windows were nailed shut) in which the girls actually worked." }\end{array}$ \\
\hline 2 & $\begin{array}{l}\text { "embellish the text by showing the very modest outfits which were considered } \\
\text { revolutionary at the time" }\end{array}$ \\
\hline 2 & $\begin{array}{l}\text { "the bride Libby hiking up the mountain (even preceding her husband) while we } \\
\text { see the a woman stranded in a long flowing dress and petticoats merely watching } \\
\text { them from the bottom" }\end{array}$ \\
\hline 3 & $\begin{array}{l}\text { "voice of the female perspective is needed as a call back to sanity -on one front } \\
\text { our soldiers are liberating concentration camp prisoners, and on another are } \\
\text { imprisoning their own citizens" }\end{array}$ \\
\hline
\end{tabular}




\begin{tabular}{|c|l|}
\hline 3 & $\begin{array}{l}\text { "their change out of cumbersome, restrictive clothing is a metaphor for release } \\
\text { from a restrictive society" }\end{array}$ \\
\hline 3 & $\begin{array}{l}\text { "treatment of women who are in transitions of making their lives better throughout } \\
\text { the book in a series of smaller and then bigger steps" }\end{array}$ \\
\hline
\end{tabular}

The module on the Culture of Deprivation: The Poor, The Dispossessed, the final unit of the course, was also analyzed using this program. The taxonomic classification for this module is slightly different but is extrapolated from the entire set of 83 messages, as illustrated in Figures 7 and 8.

Figure 7: Selected Student Response Categories

\begin{tabular}{|c|l|}
\hline $\begin{array}{c}\text { CATEGORY } \\
\text { CODE }\end{array}$ & \multicolumn{1}{|c|}{ CATEGORY CONCEPT } \\
\hline 1 & Students Extrapolate from the Textual Events to Larger Social Issues \\
\hline 2 & Students Use Illustrations to Validate Deprivation and Poverty Issues \\
\hline 3 & $\begin{array}{l}\text { Students Use Personalized Experiences and Questions to Explore Deprivation } \\
\text { Issues }\end{array}$ \\
\hline
\end{tabular}

Figure 8: Selected Student Responses by Categories

\begin{tabular}{|c|l|}
\hline $\begin{array}{c}\text { CATEGORY } \\
\text { CODE }\end{array}$ & \multicolumn{1}{c|}{ STUDENT COMMENTS } \\
\hline 1 & "feeding the hungry isn't just an act of charity" \\
\hline 1 & "testimonial to the value and richness of love verses materialistic possessions" \\
\hline 1 & "glimpse beyond the surface appearance, to see the individual" \\
\hline 1 & "gave voice to the inhabitants of the city who were previously not heard" \\
\hline 1 & $\begin{array}{l}\text { "crafted in such a way that the reader doesn't turn away from the issue but thinks } \\
\text { more about it" }\end{array}$ \\
\hline 1 & "aside from material poverty, there is a poverty of spirit in this story" \\
\hline 1 & $\begin{array}{l}\text { "thought about the irony of living in a place where people are always coming and } \\
\text { going, yet being stuck yourself" }\end{array}$ \\
\hline 1 & $\begin{array}{l}\text { "I would not be able to tell if a person is homeless just through appearances. There } \\
\text { are stereotypes here just as there are stereotypes when dealing and learning about } \\
\text { cultures different from our own." }\end{array}$ \\
\hline 2 & $\begin{array}{l}\text { "pictures, with their white borders that give the impression one is looking at a } \\
\text { scrapbook-a memory of a lesson learned" }\end{array}$ \\
\hline 2 & $\begin{array}{l}\text { "striking, unique faces and facial expressions dominate, and they exude a feeling } \\
\text { of quiet dignity" }\end{array}$ \\
\hline 2 & $\begin{array}{l}\text { "old woman's face reminded me of a stained glass representation of a religious } \\
\text { figure, especially when she is shown taking the rose off of her hat and being } \\
\text { offered a cookie" }\end{array}$ \\
\hline 2 & $\begin{array}{l}\text { "side profile of the woman removing the flower does resemble one of the figures } \\
\text { in the Chagall stained glass window at the United Nations" }\end{array}$ \\
\hline "richly detailed in color and texture, and they also contrast the reality of their \\
poverty"
\end{tabular}




\begin{tabular}{|c|l|}
\hline 3 & $\begin{array}{l}\text { "My grandfather works with the homeless and I can tell you from first-hand } \\
\text { experience that some of the guests at his soup kitchen are extremely well-dressed. } \\
\text { In order to "pass" and not be arrested, they have to do this." }\end{array}$ \\
\hline 3 & $\begin{array}{l}\text { "she was living in an abusive situation as a young adult and how, when ever she } \\
\text { left the house, she tried very hard to act as if nothing was wrong at home. She just } \\
\text { wanted to appear, to be 'normal.' And survival often requires some front of } \\
\text { normalcy as well." }\end{array}$ \\
\hline 3 & $\begin{array}{l}\text { "Is a redistribution of personal wealth a place to start in addressing the problems } \\
\text { of poverty?" }\end{array}$ \\
\hline
\end{tabular}

\section{G. Anecdotal Evidence from Conferences}

In addition to the kind of computer-assisted macro analysis above, ethnographic methods were used to collect anecdotal evidence of the power of the interaction on class discussion boards. On February 19, 1999, bell hooks spoke at a conference, "New World (Dis)Orders: Globalization, Culture, + Identity" sponsored by the Comparative Literature Department at Rutgers University. Rebecca Platzner, a PH.D. student and teaching assistant, posted her response to bell hooks on WebBoard. This excerpt from her posting, used with her permission, demonstrates the multi-layered dialogue that existed on this conference system.

For me, the issue is so much more complex than learning that I simply ought not to use certain titles. It's hard to accept that I really don't understand, and perhaps can't understand no matter how many analogies I can make to the struggles in my own life. Still, to admit that I don't know how to begin to really listen to the angry voice and yet to try to listen and to honor that voice-the voice that I believe does understanddoesn't seem a hopeless position either. It seems like an honest place to start.

I want to say just one more thing about my experience of bell hooks yesterday. It was quite wonderful for me, as "the liberal white woman academic-to-be" sitting in the audience with all my good intentions, to realize that bell hooks was not really speaking to me-she was addressing the black women in the audience. She wasn't interested in me at all (in helping me to understand her or in teaching me her point of view or in understanding me.) Understanding her and learning from her were my own problems. I can't articulate how she did it exactly, but she presented her remarks, as if I and the other "well intentioned" were invisible. She allowed me to experience the position of "other" right there on my own turf, so to speak. She didn't tell me about what it's like; she let me experience it. It was disconcerting and uncomfortable and awkward and fabulous. $\sim$ Rebecca

Examples of responses to the much longer message from Platzner included:

Your description, recognizing both the positive and negative "rush" you felt is very true and real. It's hard to examine yourself from the outside in. I went along to that lecture with a friend of mine who is black, and was expecting a little more humor than I got. I wasn't used to being in the minority, and was not prepared to hear an assault on my race, but then, I guess the point was (or is) who ever is? Susan

I can relate to your sense of "so what would you have me DO??" Sometimes it's hard to know the best role to play in what we say we all want...equality for everyone. And yet I can also understand 
bell hooks reaction to white women who talk a lot about equality and yet don't practice it in any real way, or any way that would threaten their (our) position at the center. I often have the same reaction to straight people who perceive themselves as very hip (would never admit to homophobia) and yet do not question their own heterocentrism. Kathryn

\section{CONCLUSION}

Although this study began with the intent to test Moore's theory of transactional distance, it became clear that his definitions of both structure and dialogue differ somewhat from those used by this researcher. An alternative concept of dialogue as conversation in an interpretive community rather than as teacherstudent instruction has already been presented. Moore's structure implies a single set of pre-determined objectives, activities, and assessments against which all students are evaluated. Metaphorically, that structure is a puzzle with students required to fit the precut pieces in their proper places to see the picture. The infrastructure described here is more like an array of pieces for a mosaic from which each student selects elements to make a personally meaningful image to be shared in a dialogic learning community. Of course, community dialogue may influence every aspect of that process, from initial selection of resources to final composition. Many individual images may then come together in a group-composed image as students find points of comparison, intersection, and shared identity in the community of learners.

Thus, in one sense, this course was highly structured; but that structure was flexible and relatively little structure and control were imposed on students. The number of parts and the complexities of their interrelationships in the overall course infrastructure were designed with the primary purpose of supporting learner autonomy and interaction among students rather than directing activity in the learning community. Structural elements were supportive of predetermined content while also pointing to a range of other possibilities. Within assigned topics, students were free to select from a number of resources and encouraged to bring new literature and alternative background readings into the community dialogue. The result was that student colleagues in the learning community worked together in a process that both aided personal learning and advanced knowledge building within the group. The professor participated primarily as a member of the learning community and, although present in the dialogue, restrained from assuming a traditional "teaching" role whenever possible. This constant but "restrained presence" kept transactional distance at a minimum. Perhaps these relationships were due to the nature of graduate professional education and of the students enrolled in this course. Most of the students engaged in the dialogue were active professionals who relished the opportunity to tailor course content to their own interests, needs, learning styles, and professional responsibilities.

This limited case study leaves many questions still unanswered. Further research might investigate some of the following:

- Would this course structure and form of interaction work successfully with a significantly larger number of students? With younger, less autonomous learners? With course content that is scientific, rather than aesthetic?

- What differences in course design would be necessary if the literary focus were on lengthy young adult books rather than picture books?

- In what ways would courseware that permits sophisticated tracking of students provide a better database for analysis? What privacy issues might arise with the use of such courseware?

- Can patterns of the use of various parts of the course infrastructure be identified? Do such 
patterns correspond to learning styles, learner autonomy, or previous knowledge of content?

- Do personal email exchanges between students and between teacher and a student enhance community dialogue? If so, how?

- What factors determine the relationship between faculty restraint and faculty presence in the online learning community?

What we have learned is that as active, constructivist learners, students set their own personal paces, selected individual paths. They brought unique perspectives to integrate information and ideas, contextualize content, and make connections in the virtual presence of other minds. Thus, as a group, the class created a web of relationships and a web of meanings that dramatically extended the personal and intellectual range of all participants.

\section{REFERENCES}

1. Moore, M.G. "Learner Autonomy: The Second Dimension of Independent Learning," Convergence. Vol. 5, No. 2 (1972): 76-97 and "Independent Study." In Redefining the Discipline of Adult Education. Boyd, R. and others, Editors. San Francisco: Jossey Bass, 1980, pp. 16-31 and "Editorial: Distance Education Theory," The American Journal of Distance Education. Vol. 5, No. 3 (1991) http://www.ed.psu.edu/ACSDE/ed53.html

2. Dewey, J. Experience and Education. New York: Collier Macmillan Publishers, 1938 and Dewey, J. and Bentley, A.A. Knowing and the Known. Boston, MA: Beacon Press, 1949.

3. Rosenblatt, L. Literature as Exploration. 5th Edition. New York: Modern Language Association of America, 1996 (first published in 1938) and The Reader, The Text, The Poem. Carbondale, IL: Southern Illinois University Press, 1978.

4. Fish, S.E. Is There a Text in This Class? The Authority of Interpretive Communities. Cambridge, MA: Harvard University Press, 1980.

5. Vandergrift, K.E., Platzner, R., Hannigan, J.A., Dresang, E., Lewis, A., Brizendine, S., Watson, T.T., and Satchell, V. "A Visual Interpretive Analysis Initiative: Looking and Learning Collaboratively" in Knowledge Quest. Volume 28, No. 4 (March/April 2000): 10-16.

6. Rinaldi, A. My Heart Is on the Ground: The Diary of Nannie Little Rose, A Sioux Girl. Dear America Series. New York: Scholastic, 1999 was the focus of this discussion, available at the Childlit Archives. It would also be essential to read the literary and cultural commentary available at: http://www.oyate.org/avoid.htm

7. Since this was one of the first courses in the online certificate program, many of the same students were in The Voice of the Author course with the same faculty member the following year. The experience in this second online course amply demonstrated not only the continuation of the interpretive community but also of students sharing the responsibility for both personal and group learning. It is also important to note that continuing students were very active and attentive in integrating new students into the existing interpretive community, allowing the teacher to participate more fully in the dialogue as a learner in a community of other learners.

8. Paul Kantor, professor at Rutgers University, developed this macro for analyzing messages and shared it graciously with me for the purposes of this study. The analyses included one segment of 172 messages on Gender and a second segment of 83 messages on The Culture of Deprivation: The Poor, The Dispossessed using a content analytic approach requiring a macro designed to group extracted quotations with parallel taxonomic structures into batches. Professor Paul Kantor of Rutgers University developed this macro and shared it graciously with me for the purposes of this study.

\section{ABOUT THE AUTHOR}


Kay E. Vandergrift is a Professor and Associate Dean, Director of the Information Technology \& Informatics Program, and Director of Distance Education in the Rutgers University School of Communication, Information and Library Studies, New Brunswick, New Jersey 08901. Phone 1 732-9327500 ext: 8012; e-mail kvander@scils.rutgers.edu.

URL: http://www.scils.rutgers.edu/ kvanderhttp://scils.rutgers.edu/ kvander/index.html 